ORIGINAL ARTICLE

\title{
Exposure to traffic exhausts and oxidative DNA damage
}

\author{
C-H Lai, S-H Liou, H-C Lin, T-S Shih, P-J Tsai, J-S Chen, T Yang, J J K Jaakkola, P T Strickland
}

Occup Environ Med 2005;62:216-222. doi: 10.1136/oem.2004.015107

See end of article for authors' affiliations

....................

Correspondence to:

Dr C H Lai, Department of

Public Health, National

Defence Medical Center,

Taipei, Taiwan 114, ROC;

lgh@ndmctsgh.edu.tw

Accepted 19 October 2004

\begin{abstract}
Aims: To assess the relations between exposure to traffic exhausts and indicators of oxidative DNA damage among highway toll station workers.

Methods: Cross-sectional study of 47 female highway toll station workers exposed to traffic exhausts and 27 female office workers as a reference group. Exposure assessment was based on average and cumulative traffic density and a biomarker of exposure, urinary 1-hydroxypyrene-glucuronide (1-OHPG). Urinary 8-hydroxydeoxyguanosine (8-OHdG) was used as a biomarker of oxidative DNA damage. Plasma nitric oxide (NO) was measured as an indicator of oxidative stress related to traffic exhaust exposure.

Results: The mean concentration of urinary $8-\mathrm{OHdG}$ was substantially higher among the exposed nonsmokers $(13.6 \mu \mathrm{g} / \mathrm{g}$ creatinine) compared with the reference non-smokers $(7.3 \mu \mathrm{g} / \mathrm{g}$ creatinine; difference $6.3,95 \% \mathrm{Cl} 3.0$ to 9.6$)$. The mean concentration of $\mathrm{NO}$ among the exposed $(48.0 \mu \mathrm{mol} / \mathrm{l})$ was also higher compared with the reference non-smokers $(37.6 \mu \mathrm{mol} / \mathrm{l}$; difference $10.4,95 \% \mathrm{Cl}-0.4$ to 21.2). In linear regression adjusting for confounding, a change in $\log (8-\mathrm{OHdG})$ was statistically significantly related to a unit change in $\log (1-\mathrm{OHPG})(\beta=0.372,95 \% \mathrm{Cl} 0.081$ to 0.663$)$.

Conclusions: Results indicate that exposure to traffic exhausts increases oxidative DNA damage. Urinary $8-\mathrm{OHdG}$ is a promising biomarker of traffic exhaust induced oxidative stress.
\end{abstract}

$\mathrm{T}$ raffic exhausts constitute a complex mixture of byproducts of the combustion process including hundreds of pollutants in gaseous and particulate phases. Most of the particulate phase constitutes fine-mode particulate matter, which is derived from combustion processes that has volatilised and then condensed to form primary particles or from precursor gases reacting in the atmosphere to form secondary particles. Epidemiological studies have suggested that exposure to atmospheric particulate matter is associated with an increased risk of morbidity and mortality, but the mechanism remains unclear. ${ }^{12}$

It has been suggested that reactive oxygen species (ROS) and reactive nitrogen species (RNS) are involved in aging, mutagenesis, and carcinogenesis. ${ }^{3}{ }^{4}$ ROS include superoxide, hydrogen peroxide, and hydroxyl radical. RNS include nitric oxide and its derivates such as nitrogen dioxide and peroxynitrite. Particles in traffic exhausts can produce a significant amount of ROS. The smaller particles in ambient aerosols have higher ROS contents. ${ }^{5}$ Fine particles from traffic exhausts also contain polycyclic aromatic hydrocarbons (PAHs), ${ }^{6-8}$ and some of them are known or suspected human carcinogens. ${ }^{9}$ Pyrene is commonly found in mixtures of PAHs; it has metabolites such as l-hydroxypyrene (1-OHP) and 1-hydroxypyrene-glucuronide (1-OHPG), which can be measured in human urine. These metabolites have previously been used as biomarkers of recent exposure to traffic exhaust; recent findings indicate that exposure to traffic exhausts increases the urinary concentration of l-OHPG with a dose-response pattern suggesting that it might be a useful biomarker for vehicle exhaust exposure. ${ }^{10}$ The intermediate metabolites of PAH having electrophilic properties can covalently attach to intracellular macromolecules, leading to the generation of ROS, and thus possibly contributing to the development of disease. ${ }^{11}{ }^{12}$ Nitric oxide (NO) is a free radical gas that plays an important role in neurotransmission, vasodilatation, and immune defence. ${ }^{13}$ It is synthesised from L-arginine by nitric oxide synthase. There is evidence that oxidative stress induced by traffic exhaust is associated with the impairment of NO production. ${ }^{12-14}$ Plasma nitrite levels, representative of NO production, are determined in plasma. In pulmonary vessels, NO is a vasodilator, but in excess it may be cytotoxic and cause further damage to the surrounding epithelium and endothelium. ${ }^{13}{ }^{14}$ In airways epithelium, NO modulates the immune response.

Attacks on DNA by reactive oxygen species frequently result in oxidative DNA damage. Urinary 8-hydroxydeoxyguanosine $(8-\mathrm{OHdG})$ is a biomarker of oxidative DNA stress, reflecting its repair from DNA. 8-OHdG is a modified base that occurs in DNA due to attack by hydroxyl radicals that are formed as products and intermediates of aerobic metabolism and during oxidative stress. Biomonitoring in humans has shown that 8-OHdG may correlate with oxidative stress and damage to DNA. ${ }^{15-17}$

The overall objective of the present study was to study the relation between exposure to high levels of traffic exhausts and the occurrence of oxidative DNA damage. We assessed the exposure using measures of traffic density and urinary 1-OHPG. Urinary 8-OHdG was used as a measure of oxidative DNA damage. We also assessed the levels of plasma NO as a biomarker of oxidative stress related to traffic exhaust exposure.

\section{MATERIALS AND METHODS}

\section{Study population}

We carried out a cross-sectional study among female toll station workers with occupational exposure to traffic exhausts and a reference group of female workers who were in classroom training to become toll station workers, which has been described previously. ${ }^{10}$ Briefly, we recruited all toll station workers in a highway toll station in the Taipei metropolitan area, Taiwan. The toll station is located on the First Highway, $10 \mathrm{~km}$ south from Taipei City. According to

Abbreviations: 1-OHP, 1-hydroxypyrene; 1-OHPG, 1-hydroxypyreneglucuronide; 8-OHdG, 8-hydroxydeoxyguanosine; eNOS, endothelial nitric oxide synthase; iNOS, inducible nitric oxide synthase; NO, nitric oxide; PAHs, polycyclic aromatic hydrocarbons; ROS, reactive oxygen species; RNS, reactive nitrogen species 


\section{Main messages}

- Subjects exposed to high levels of traffic exhausts had substantially higher levels of urinary 8-OHdG and plasma NO compared with the reference group.

- Traffic exhausts, possibly metabolites of PAHs, may form an electrophilic derivative that binds to DNA and may involve ROS. Such changes may include ROS induced DNA strand breaks, base modifications, oxidative modification of DNA, and result in increasing urinary 8-OHdG levels.

- Exposure to traffic exhausts may induce endothelial cell nitric oxide synthase, leading to increase in plasma $\mathrm{NO}$ concentrations and pathophysiological changes in vascular tone.

the Bureau of Highways records, this toll station had the highest traffic density among all toll stations in Taiwan. All the toll workers work in three shifts: morning (from $800 \mathrm{am}$ to $400 \mathrm{pm}$ ), evening (from $400 \mathrm{pm}$ to $0000 \mathrm{am}$ ), and night shift (from $0000 \mathrm{am}$ to $800 \mathrm{am}$ ). There are 20 tollbooths10 are used to collect the toll of traffic flow from Taipei City to Taipei County (from north to south), and the remaining 10 booths collect toll from the opposite traffic flow. Of the 10 booths in both directions, 2-3 were designed for bus and truck traffic. The other $7-8$ booths were for cars and vans. These lanes are divided into those using prepaid tickets and those using cash payment. The number of open booths depends on the traffic flow. The workers followed a schedule, which defined the shift and the type of lane. As a rule, they worked four days in a row and then took one day off. There was a continuous rotation of lanes from one day to another. The duration of the working day was eight hours and the workers were allowed to take a 30-45 minute break every 1-2 hours. The exposed group included 47 toll station workers. The reference group consisted of 27 office workers.

\section{Exposure assessment}

Exposure assessment was based on measures of traffic density and urinary biomarker levels. Traffic density was expressed as both dichotomous and continuous variables. The dichotomous exposure variable was based on the type of work: toll collection or office work. The continuous exposure variables were based on source strength in the microenvironment and time-activity of the worker during the working day. First, we applied average lane specific traffic density in vehicles per hour, separating the vehicles into buses and trucks or personal cars. Second, we assessed cumulative exposure by multiplying traffic density (vehicles per hour) by the time spent at the toll booth (hours); the unit was expressed in the number of vehicles per working day. The biomarker of exposure to traffic exhaust was urinary concentration of 1-hydroxypyrene-glucuronide (1-OHPG) after the working shift.

\section{Outcome assessment}

The outcome of interest was oxidative DNA damage. We used the concentration of 8-hydroxydeoxyguanosine (8-OHdG) in the urine after the working shift as the biomarker of effect of exposure to traffic exhausts on DNA. In addition, we used plasma nitric oxide (NO) after the working shift as a biomarker of effect on NO production.

\section{Data collection}

In the beginning of the study, we distributed a selfadministered questionnaire to the participants, which

\section{Policy implications}

- Current levels of occupational exposure to traffic exhausts from motor vehicles should be reduced.

inquired about personal characteristics, such as age, education, marital status, and smoking habits; mode of transportation to work; a history of diseases; consumption of broiled, grilled, and barbecued food; use of cooking fuel; cooking practice; use of incense, candles, and mosquito coils; and use of personal protective equipment. Workers were asked to collect a post-shift urine sample in a container. Venous blood was also collected post-shift, drawn into Vacutainers (Becton Dickinson, Rutherford, New Jersey) containing sodium heparin, centrifuged at $4^{\circ} \mathrm{C}$ for 10 minutes at $1200 \mathrm{~g}$, protected from light, and stored at $-80^{\circ} \mathrm{C}$.

This study was approved by the institutional review boards at the Tri-Service General Hospital, Taipei, Taiwan. All the participants signed informed consent prior to study enrolment.

\section{Analysis of urinary 1-OHPG}

The urine samples were collected in brown polyethylene $500 \mathrm{ml}$ containers and labelled with subject identification number, date, and time. The samples were transported in a cooler. Urine samples were divided into several small volume aliquots and stored at $-80^{\circ} \mathrm{C}$ to minimise the effect of freezethaw on the stability of specimens. Urine samples $(2 \mathrm{ml})$ were treated with $0.1 \mathrm{~N} \mathrm{HCl}\left(90^{\circ} \mathrm{C}\right)$ to hydrolyse acid labile metabolites, as described previously. ${ }^{18}$ The hydrolysed samples were loaded onto Sep-Pak C18 cartridges (Waters) and washed with methanol ( $30 \%$ in water). The relatively nonpolar metabolites were eluted with methanol ( $80 \%$ in water; $4 \mathrm{ml}$ ) and the volume was reduced to $0.5 \mathrm{ml}$ by a centrifugal and vacuum evaporator (Eyela CVE-100, Tokyo, Japan). The concentrated samples were diluted to $4 \mathrm{ml}$ with $15 \mathrm{mM}$ phosphate buffered saline (PBS). Immunoaffinity columns were prepared using poly-prep columns $(0.8 \times 4 \mathrm{~cm})$ filled with $\mathrm{CNBr}$ activated Sepharose $4 \mathrm{~B}(0.8 \mathrm{ml})$ coupled with monoclonal antibody 8E11, which recognises several PAHDNA adducts and metabolites. Monoclonal antibody 8E1l was obtained from Trevigen, Inc., Gaithersburg, MD, USA. It was originally produced against benzo[a]pyrene-diolepoxide modified DNA, and has been shown to recognise 1-OHPG. ${ }^{18}$ After washing the columns twice with $4 \mathrm{ml}$ of $15 \mathrm{mM}$ PBS, samples in phosphate buffered saline were loaded on columns and bound material was eluted with $2 \mathrm{ml}$ of $40 \%$ methanol. Eluted fractions were quantified by synchronous fluorescence spectroscopy (SFS) using a Perkin-Elmer LS 50B luminescence spectrometer. The excitation-emission monochromators were driven synchronously with a wavelength difference of $34 \mathrm{~nm}$. 1-OHPG, purchased from the National Cancer Institute (NCI) Chemical Carcinogen Repository (MRI, Kansas City, MO, USA), produces a characteristic fluorescence emission maximum at $381 \mathrm{~nm}$ (347 nm excitation). Fluorescence intensity was used to quantify l-OHPG, as described previously. ${ }^{18}{ }^{19}$ The recovery of the assay was $80 \%$. The coefficient of variation of the assay was $8-10 \%$ during the period of sample analysis. The limit of detection was $0.06 \mathrm{pmol} / \mathrm{ml}$ as determined by the concentration of the standard at which the signal-to-noise ratio was 3 . The urinary 1-OHPG concentrations were normalised to urine creatinine. Creatinine was determined spectrophotometrically (PerkinElmer Lambda 5 model) with a commercial kit (Boehringer, Mannheim, Germany) based on Jaff's basic picrate method. 


\section{Analysis of 8-OHdG}

Levels of urinary 8 -OHdG were determined by indirect competitive enzyme linked immunosorbent assay (ELISA) (New 8-OHdG Check; Institute for the Control of Aging, Fukuroi, Shizuoka, Japan) according to Chuang and colleagues $^{15}$ and Maeshima and colleagues. ${ }^{20}$ Urine samples were thawed and centrifuged at $2000 \mathrm{rpm}$ for 10 minutes to obtain the opaque layer. A $50 \mu \mathrm{l}$ aliquot of sample or standard and $50 \mu \mathrm{l}$ of primary monoclonal antibodies were added to microtitre plates pre-coated with 8 -OHdG. The plates were then incubated at $37^{\circ} \mathrm{C}$ for 1 hour with continuous mixing at $100 \mathrm{rpm}$. The bounding of free 8-OHdG were washed with $250 \mu \mathrm{l}$ phosphate buffered saline. Horseradish peroxidase (HRP) conjugated secondary antibodies $(100 \mu \mathrm{l})$ were added to each well and then the plates were incubated for 1 hour with mixing. The unbound secondary antibody was washed away. A $100 \mu \mathrm{l}$ aliquot of chromatic substrate was added to each well and incubated in the dark at room temperature for 15 minutes; $100 \mu \mathrm{l}$ of $1.0 \mathrm{M}$ phosphoric acid was added to terminate the reaction. The absorbance was measured at $450 \mathrm{~nm}$ with a computer controlled ELISA reader (MRXII, Dynex Technologies, VA, USA). The concentration of 8-OHdG of the urine samples was interpolated from a standard curve drawn with the assistance of logarithmic transformation. The coefficient of variation of the assay was within $6 \%$ during the period of sample analysis. The results were expressed as $\mu \mathrm{g} / \mathrm{g}$ creatinine.

\section{Analysis of plasma nitric oxide}

To one aliquot of plasma $100 \mu \mathrm{l}$ ethanol was added; it was then centrifuged for 30 minutes at $15000 \mathrm{~g}$. To avoid potential contamination due to storage, a volume of $10 \mu \mathrm{l}$ of supernatant was immediately assayed by the NO/ozone chemiluminescence technique (NO-Analyzer 280 A, Sievers Research Inc., Boulder, CO) as described previously. ${ }^{21}$ Briefly, we measured the oxidation products $\left(\mathrm{NO}_{2}{ }^{-}\right)$of $\mathrm{NO}$ using a reaction vessel containing a reducing system $(0.1 \mathrm{M}$ vanadium chloride, Aldrich Co., Germany). Detection of NO was then completed by its reaction with ozone, which lead to the emission of red light ( $\mathrm{NO}+\mathrm{O}_{3} \rightarrow \mathrm{NO}_{2}{ }^{*}+\mathrm{O}_{2} ; \mathrm{NO}_{2}{ }^{*} \rightarrow \mathrm{NO}_{2}+$ hv). Standard curves were made before each measurement by a mean of three injections of each concentration $(1,3,5$, $10 \mu \mathrm{M} \mathrm{NO}$ ), which were prepared using freshly prepared solutions of $\mathrm{NaNO}_{2}(10 \mu \mathrm{l})$ in distilled water. The correlation between the above mentioned four nitrite concentrations and the integrated areas of their peaks was linear. The correlation coefficient was 0.984 . The results were expressed as $\mu \mathrm{mol} / \mathrm{l}$.

\section{Statistical methods}

First, we compared the distributions of 8 -OHdG and NO concentrations between the exposed and the reference group. The 8-OHdG concentrations were roughly normally distributed (skewness 1.07, kurtosis 4.20, Shapiro-Wilk W test for normal data $\mathrm{p}=0.09$ ) and therefore we assessed the difference in means using the unpaired $t$ test. We also compared the distributions using a non-parametric Wilcoxon rank-sum test. We estimated the relation between the 8-OHdG concentration and the determinants of interest in linear regression analysis adjusting for confounding. Second, we studied the relations of traffic density to urinary 8-OHdG and plasma NO concentrations in linear regression models. We fitted the two types of exposure variables described above: average traffic density (vehicles per hour) and cumulative traffic density (number of vehicles). The covariates used in the analyses included: age (18-24, 25-29, 30-), marital status (married versus unmarried), education (college versus high school), use of motorcycle as main transportation (yes/no), frequent exposure to incense (yes/ no), and frequent use of a protective mask (yes/no). We also fitted similar models using log transformed outcome variables. Finally, we elaborated the relation of $8-\mathrm{OHdG}$ to 1-OHPG, and NO using plots and linear regression analysis adjusting for potential confounders such as age, marital status, smoking, use of motorcycle, and burning of incense. The regression diagnostics indicated heteroscedasticity-that is, increasing variance of the dependent variable by increasing magnitude of the independent parameters (for both relations). We applied log transformations to meet the assumptions of linear regression, which improved the fit in both cases. All the analyses were performed with the STATA 7 statistical package.

\section{RESULTS}

\section{Study population}

Characteristics of the study population were compared between the exposed and the reference workers (table 1). The mean age was 25.7 years (SD 5.71) in the exposed and 27.0 years (SD 4.71) in the reference workers. The exposed subjects were less often married $(6 \% v 30 \%)$ and had a higher educational background than the reference group. The prevalence of current smoking was lower among the exposed (11\%) compared with the reference group (30\%). Among current smokers, the mean daily smoking rate was lower among the exposed (8 cigarettes/day) than among the reference group (13 cigarettes/day). The exposed subjects used a motorcycle less often for transportation and were less frequently exposed to incense burning compared with the reference group. The mean BMI was $21.2 \mathrm{~kg} / \mathrm{m}^{2}$ (SD 3.2) in the exposed and $21.3 \mathrm{~kg} / \mathrm{m}^{2}$ (SD 4.1 ) in the reference group.

\section{Comparison of urinary 8-hydroxydeoxyguanosine and plasma nitric oxide between exposed and reference groups}

The percentage of smokers was greater in the reference group $(30 \%, \mathrm{n}=8)$ than in the exposed group $(11 \%, \mathrm{n}=5)$. To exclude the smoking effect, a stratified analysis was performed. The mean concentration of urinary 8-OHdG was $10.5 \mu \mathrm{g} / \mathrm{g}$ creatinine (SD 8.2) among the exposed smokers and $10.2 \mu \mathrm{g} / \mathrm{g}$ creatinine (SD 4.6) in the reference smokers. The mean concentration of urinary 8-OHdG was $13.6 \mu \mathrm{g} / \mathrm{g}$ creatinine (SD 7.3, median 15.1, 25th centile 8.2, 75th centile 18.3 ) among the exposed subjects and $7.3 \mu \mathrm{g} / \mathrm{g}$ creatinine (SD 4.8, median 7.7, 25th centile 3.2, 75th centile 10.3) in the reference group. The difference, $6.3 \mu \mathrm{g} / \mathrm{g}$ creatinine $(95 \% \mathrm{CI}$ 2.98 to 9.64 ), was not likely to be explained by chance ( $t$ test: $\mathrm{p}=0.004$; Wilcoxon rank sum test: $\mathrm{p}=0.0022$ ). We fitted a linear regression model for 8 -OHdG adjusting for the covariates in table 1 . The adjusted difference in the mean urinary 8 -OHdG concentration was 4.68 (95\% CI 0.14 to 9.21).

The mean concentration of plasma nitric oxide was $58.7 \mu \mathrm{mol} / \mathrm{l}$ (SD 19.5) among the exposed smokers and $40.1 \mu \mathrm{mol} / \mathrm{l}$ (SD 10.0) in the reference smokers. The mean concentration of NO was $48.0 \mu \mathrm{mol} / \mathrm{l}$ (SD 23.8, median 42.6, 25 th centile 28.4 , 75th centile 64.1) among the exposed nonsmokers and $37.58 \mu \mathrm{mol} / \mathrm{l}$ (SD 14.1, median 37.4, 25th centile $27.4,75$ th centile 47.4$)$ in the reference non-smokers with a difference of $10.48 \mu \mathrm{mol} / \mathrm{l}$ (95\% CI -0.4 to 21.2 ) (unpaired $t$ test: $\mathrm{p}=0.1 \mathrm{l}$; Wilcoxon rank sum test: $\mathrm{p}=0.25$ ).

When NO data from smokers and non-smokers were analysed together, the mean concentration for the exposed workers was 49.1 (SD $23.4 \mu \mathrm{mol} / \mathrm{l}$ ) and for the unexposed workers 38.4 (SD $12.7 \mu \mathrm{mol} / \mathrm{l})$ ( $t$ test: $\mathrm{p}=0.03$; Wilcoxon rank sum test: $p=0.16$ ). When we fitted a linear regression model for NO adjusting for the covariates presented in table 1 the adjusted difference in the mean NO concentration was 18.78 (95\% CI 5.48 to 32.08 ). 
Table 1 Characteristics of the study population

\begin{tabular}{|c|c|c|c|c|c|c|c|}
\hline \multirow[b]{2}{*}{ Characteristic } & \multicolumn{2}{|c|}{ Exposed } & \multicolumn{2}{|c|}{ Reference } & \multicolumn{2}{|c|}{ Total } & \multirow[b]{2}{*}{ p value } \\
\hline & $\mathbf{n}$ & $\%$ & $\mathbf{n}$ & $\%$ & $\mathbf{n}$ & $\%$ & \\
\hline Number of subjects & 47 & 63.5 & 27 & 36.5 & 74 & 100 & \\
\hline \multicolumn{8}{|l|}{ Age } \\
\hline $18-24$ & 24 & 51.1 & 7 & 25.9 & 31 & 41.9 & \multirow[t]{3}{*}{0.04} \\
\hline $25-29$ & 10 & 21.3 & 13 & 48.2 & 23 & 31.1 & \\
\hline $30-$ & 13 & 27.6 & 7 & 25.9 & 20 & 27.0 & \\
\hline \multicolumn{8}{|l|}{ Marital status } \\
\hline Married & 3 & 6.4 & 8 & 29.6 & 11 & 14.9 & \multirow[t]{2}{*}{0.007} \\
\hline Single & 44 & 93.6 & 19 & 70.3 & 63 & 85.1 & \\
\hline \multicolumn{8}{|l|}{ Education } \\
\hline High school & 30 & 63.8 & 26 & 96.3 & 56 & 75.7 & \multirow[t]{2}{*}{0.002} \\
\hline College & 17 & 36.2 & 1 & 3.7 & 18 & 24.3 & \\
\hline \multicolumn{8}{|l|}{ Current smoking habits } \\
\hline Smokers & 5 & 10.6 & 8 & 29.6 & 13 & 17.6 & \multirow[t]{2}{*}{0.03} \\
\hline Non-smokers & 42 & 89.4 & 19 & 70.4 & 61 & 82.4 & \\
\hline \multicolumn{8}{|l|}{ Transportation } \\
\hline Motorcyclist & 6 & 12.8 & 16 & 59.3 & 22 & 29.7 & \multirow[t]{2}{*}{$<0.001$} \\
\hline Others & 41 & 87.2 & 11 & 40.7 & 52 & 70.3 & \\
\hline \multicolumn{8}{|l|}{ Daily use of incense } \\
\hline Yes & 8 & 17.0 & 16 & 59.3 & 24 & 32.4 & \multirow[t]{2}{*}{$<0.001$} \\
\hline No & \multirow{2}{*}{\multicolumn{2}{|c|}{$21.23(3.22)$}} & & 40.7 & & 67.6 & \\
\hline BMI $\left(\mathrm{kg} / \mathrm{m}^{2}\right)^{*}$ & & & \multicolumn{2}{|c|}{$21.32(4.07)$} & \multicolumn{2}{|c|}{$21.26(3.52)$} & 0.47 \\
\hline
\end{tabular}

Relations between average traffic density and urinary 8-OHdG and plasma nitric oxide concentrations

We examined the relation between traffic density and the urinary concentration of 8-OHdG. We estimated the relations between the average and the cumulative exposure to traffic exhausts and the concentration of 8-OHdG in linear regression adjusting for potential confounding factors (table 3). The estimates were given for non-smokers $(\mathrm{n}=42)$ and separately for buses and trucks $(\mathrm{n}=13)$ and personal cars $(\mathrm{n}=17)$. The 8 -OHdG concentration was related to exposure to both personal cars and trucks and buses, although neither was statistically significant (table 3). There was a $9.32 \mu \mathrm{g} / \mathrm{g}$ creatinine $(95 \% \mathrm{CI}-11.59$ to 30.23 ) increase per 1000 cars/hour increase in average traffic density. The corresponding estimate for trucks and buses was of greater magnitude, 16.76 ( $95 \%$ CI -13.63 to 47.16 ). There was an increase of 8 -OHdG in relation to cumulative exposure to trucks and buses $(7.10 \mu \mathrm{g} / \mathrm{g}$ creatinine per 1000 vehicles, $95 \%$ CI -7.16 to 21.35$)$, but no apparent association for personal cars $(0.67,95 \%$ CI -2.45 to 3.79$)$. There was a $0.38 \mu \mathrm{g} / \mathrm{g}$ creatinine increase per 1000 cars/hour (95\% CI -0.55 to 1.30 ) increase in average traffic density. The corresponding estimate for trucks and buses was of lesser magnitude, $0.15 \mu \mathrm{g} / \mathrm{g}$ creatinine (95\% CI -1.30 to 1.59 ). Table 3 presents the similar models using a log transformed outcome variable. There was a non-significant increase of $\log (8-\mathrm{OHdG})$ in relation to cumulative exposure to trucks and buses $(0.13 \mu \mathrm{g} / \mathrm{g}$ creatinine per 1000 vehicles, 95\% CI -0.50 to 0.76 ), but no apparent association for personal cars $(0.07,95 \%$ CI -0.07 to 0.22$)$.

The plasma NO concentration was related to both personal cars and trucks and buses, although neither was statistically significant (table 4). There was a $2.65 \mu \mathrm{mol} / \mathrm{l}$ (95\% CI -92.82 to 98.12 ) increase per 1000 cars/hour increase in average traffic density. The corresponding estimate for trucks and buses was of greater magnitude $(160.48,95 \%$ CI -19.56 to

Table 2 Concentration of plasma NO, and urinary 1-OHPG and 8-OHdG measured for exposed and reference groups by smoking status

\begin{tabular}{|c|c|c|c|c|c|}
\hline & \multicolumn{2}{|c|}{ Exposed group } & \multicolumn{2}{|c|}{ Reference group } & \multirow[b]{2}{*}{ p value* } \\
\hline & $\mathbf{n}$ & Mean (SD) & $n$ & Mean (SD) & \\
\hline \multicolumn{6}{|l|}{ 8-OHdG } \\
\hline Smokers & 5 & $10.2(4.6)$ & 8 & $10.5(8.2)$ & 0.94 \\
\hline Non-smokers & 42 & $13.6(7.3)$ & 16 & $7.3(4.8)$ & 0.0004 \\
\hline Subtotal & 47 & $13.3(7.1)$ & 24 & $8.4(6.2)$ & 0.004 \\
\hline p value† & & 0.19 & & 0.34 & \\
\hline \multicolumn{6}{|l|}{ NO } \\
\hline Smokers & 4 & 58.7 (19.5) & 8 & $40.1(10.0)$ & 0.15 \\
\hline Non-smokers & 35 & $48.0(23.8)$ & 16 & $37.6(14.1)$ & 0.06 \\
\hline Subtotal & 39 & $49.1(23.4)$ & 24 & 38.4 (12.7) & 0.03 \\
\hline p valuet & & 0.365 & & 0.63 & \\
\hline \multicolumn{6}{|l|}{ 1-OHPG } \\
\hline Smokers & 5 & $0.16(0.10)$ & 8 & $0.18(0.07)$ & 0.69 \\
\hline Non-smokers & 42 & $0.12(0.07)$ & 16 & $0.07(0.04)$ & 0.01 \\
\hline Subtotal & 47 & $0.12(0.08)$ & 24 & $0.11(0.07)$ & 0.63 \\
\hline p valuet & & 0.35 & & 0.003 & \\
\hline
\end{tabular}

Values shown are mean (SD).

${ }^{*}$ Comparison between the exposed and reference groups.

tComparison between the smokers and non-smokers.

8-OHdG, 8-hydroxy-2'deoxyguanosine $(\mu \mathrm{g} / \mathrm{g}$ creatinine); NO, nitrogen oxides ( $\mu \mathrm{mol} / \mathrm{l}) ; 1-\mathrm{OHPG}$

1-hydroxypyrene-glucuronide $(\mu \mathrm{mol} / \mathrm{mol}$ creatinine). 
Table 3 Relations between traffic density and the urinary $8-\mathrm{OHdG}(\mu \mathrm{g} / \mathrm{g}$ creatinine) concentration in the toll station workers among non-smokers $(n=42)$

\begin{tabular}{|c|c|c|c|c|c|c|c|c|}
\hline & \multicolumn{4}{|c|}{ Increase in $8-\mathrm{OHdG}$} & \multicolumn{4}{|c|}{ Increase in $\log (8-\mathrm{OHdG})$} \\
\hline & \multicolumn{2}{|c|}{ Unadjusted } & \multicolumn{2}{|c|}{ Adjusted* } & \multicolumn{2}{|c|}{ Unadjusted } & \multicolumn{2}{|c|}{ Adjusted* } \\
\hline & B & $95 \% \mathrm{Cl}$ & B & $95 \% \mathrm{Cl}$ & B & $95 \% \mathrm{Cl}$ & B & $95 \% \mathrm{Cl}$ \\
\hline $\begin{array}{l}\text { Average exposure to cars (per } \\
1000 \text { vehicles/hour) }\end{array}$ & 4.16 & -15.64 to 23.96 & 9.32 & -11.59 to 30.23 & 0.20 & -1.05 to 1.45 & 0.38 & -0.55 to 1.30 \\
\hline $\begin{array}{l}\text { Average exposure to trucks and } \\
\text { buses (per } 1000 \text { vehicles/hour) }\end{array}$ & 19.15 & -8.11 to 46.41 & 16.76 & -13.63 to 47.16 & 0.58 & -1.03 to 2.19 & 0.15 & -1.30 to 1.59 \\
\hline $\begin{array}{l}\text { Cumulative exposure to cars (per } \\
1000 \text { vehicles) }\end{array}$ & 0.15 & -2.62 to 2.92 & 0.67 & -2.45 to 3.79 & 0.03 & -0.15 to 0.20 & 0.07 & -0.07 to 0.22 \\
\hline $\begin{array}{l}\text { Cumulative exposure to trucks } \\
\text { and buses (per } 1000 \text { vehicles) }\end{array}$ & -0.09 & -0.82 to 0.64 & 7.10 & -7.16 to 21.35 & -0.09 & -0.824 to 0.64 & 0.13 & -0.50 to 0.76 \\
\hline
\end{tabular}

340.53). The adjusted increase of NO in relation to cumulative exposure per 1000 vehicles was also greater for trucks and buses $(29.11,95 \%$ CI -17.98 to 76.20$)$ compared to personal cars $(4.97,95 \%$ CI -9.40 to 19.34$)$. A similar pattern was found when using $\operatorname{logNO}$ as the outcome variable, as shown in table 4 .

\section{Relations of urinary 8-OHdG to urinary 1-OHPG and plasma NO}

A plot presentation indicated a monotonous increase of 8-OHdG by 1-OHPG. The graphical presentation as well as regression diagnostics indicated strong heteroscedasticity, which was corrected by log-log transformation. There was a significant linear relation between $\log (8-\mathrm{OHdG})$ and $\log$ (1-OHPG), as shown in table 5 . In linear regression adjusting for confounding, a change in $\log (8-\mathrm{OHdG})$ was statistically significantly related to a unit change in $\log (1-\mathrm{OHPG})$ $(\beta=0.372$, 95\% CI 0.081 to 0.663$)$. Adjustment for confounding weakened the relation only slightly. There was no significant association between 8-OHdG and NO or corresponding log transformed parameters.

\section{DISCUSSION}

The findings of the present study indicate an increased amount of DNA damage measured using urinary 8-OHdG in subjects working under conditions of potential oxidative stress due to exposure to traffic exhausts. Non-smoking female toll workers exposed to traffic pollutants had on average $90 \%$ and $30 \%$ higher levels of urinary 8 -OHdG and plasma NO, respectively, compared with female office workers. There was a statistically significant linear relation between the log transformed urinary exposure biomarker (1-OHPG) and the urinary measure of DNA damage (8-OHdG). This relation did not change substantially when adjusting for determinants of 8 -OHdG such as cigarette smoking and use of motorcycle in transportation.

\section{Validity of results}

In order to achieve comparability of the two groups, we selected a reference group from women who were in training to become toll station workers, but not yet exposed to high levels of traffic exhausts at work. Nevertheless, the two occupational groups differed in certain potential determinants of urinary 8-OHdG, which might have influenced the comparison. The groups were comparable as to gender (all women) and age. However, smoking was a strong determinant of urinary 8-OHdG levels and there were more smokers among the office workers (Pearson's $\chi^{2}=4.27, \mathrm{p}=0.039$ ) chosen for the reference group compared with toll workers considered to be exposed. Restricting the analyses to nonsmokers eliminated the influence of smoking. We also applied linear regression analysis to adjust for other potential confounders. In assessing the relation between traffic density and $8-\mathrm{OHdG}$ and NO levels among the exposed toll station workers, the study design minimised potential selection bias. The traffic lane for the studied workplace was selected for each participant from a rotating schedule. Thus the occupational exposure level was allocated independently from personal characteristics or other determinants of 8 -OHdG and NO. The occupational exposure during the studied working days could have been, by chance, related to other factors influencing urinary 8-OHdG and NO; therefore we also fitted multivariate linear regression models with all the potential confounders. In general, the adjustment for covariates strengthened the relation for both truck and bus and car traffic density and the urinary 8-OHdG concentrations. The adjustment had little effect on the relation between personal car traffic density and NO concentrations,

Table 4 Relations between traffic density and the $\mathrm{NO}(\mu \mathrm{mol} / \mathrm{l})$ concentration in the toll station workers among non-smokers ( $n=42)$

\begin{tabular}{|c|c|c|c|c|c|c|c|c|}
\hline & \multicolumn{4}{|c|}{ Increase in NO } & \multicolumn{4}{|c|}{ Increase in $\log (\mathrm{NO})$} \\
\hline & \multicolumn{2}{|c|}{ Unadjusted } & \multicolumn{2}{|c|}{ Adjusted* } & \multicolumn{2}{|c|}{ Unadjusted } & \multicolumn{2}{|c|}{ Adjusted* } \\
\hline & B & $95 \% \mathrm{Cl}$ & B & $95 \% \mathrm{Cl}$ & B & $95 \% \mathrm{Cl}$ & B & $95 \% \mathrm{Cl}$ \\
\hline $\begin{array}{l}\text { Average exposure to cars (per } \\
1000 \text { vehicles/hour) }\end{array}$ & 16.36 & -63.62 to 96.34 & 2.65 & -92.82 to 98.12 & 0.25 & -0.29 to 0.79 & 0.22 & -0.65 to 1.09 \\
\hline $\begin{array}{l}\text { Average exposure to trucks and } \\
\text { buses (per } 1000 \text { vehicles/hour) }\end{array}$ & 127.59 & -17.34 to 272.52 & 160.48 & -19.56 to 340.53 & 0.62 & -0.90 to 2.13 & 1.24 & -0.26 to 2.75 \\
\hline $\begin{array}{l}\text { Cumulative exposure to cars } \\
\text { (per } 1000 \text { vehicles) }\end{array}$ & 8.77 & -1.09 to 18.63 & 4.97 & -9.40 to 19.34 & 0.08 & 0.01 to 0.14 & 0.08 & -0.03 to 0.19 \\
\hline $\begin{array}{l}\text { Cumulative exposure to trucks } \\
\text { and buses (per } 1000 \text { vehicles) }\end{array}$ & 21.19 & -13.78 to 56.17 & 29.11 & -17.98 to 76.20 & 0.15 & -0.12 to 0.42 & 0.26 & -0.02 to 0.54 \\
\hline
\end{tabular}


Table 5 Simple linear regression of $\log (8-\mathrm{OHdG})$ by $\log (1-\mathrm{OHPG})$ and a general linear regression with potential confounders as covariates $(n=71)$

\begin{tabular}{lrrrr}
\hline Variable & $\boldsymbol{\beta}$ & (SE $\boldsymbol{\beta})^{*}$ & $\boldsymbol{t}$ & \multicolumn{1}{c}{$\mathbf{9 5 \%} \mathrm{Cl}$} \\
\hline $\begin{array}{l}\text { Unadjusted relation } \\
\text { Log(1-OHPG) }\end{array}$ & 0.377 & 0.121 & 3.12 & 0.136 to 0.619 \\
& & & & \\
Adjusted relation & & & & \\
Log(1-OHPG) & 0.372 & 0.145 & 2.57 & \multicolumn{1}{l}{0.081 to 0.663} \\
Age & -0.01 & 0.009 & -1.14 & -0.028 to 0.008 \\
Marital status (married/single) & -0.274 & 0.147 & -1.86 & -0.571 to -0.021 \\
Exposed $v$ reference group & 0.129 & 0.108 & 1.20 & -0.087 to 0.346 \\
Current smoking (smoker/non-smoker) & 0.021 & 0.124 & 0.17 & -0.227 to 0.269 \\
Transportation (motorcyclist/others) & -0.241 & 0.110 & -2.20 & -0.461 to -0.022 \\
Daily burning of incense (yes/no) & 0.032 & 0.067 & 0.48 & -0.102 to 0.166 \\
\hline SE $\beta=$ standard error of $\beta$ coefficient. & & & & \\
\hline
\end{tabular}

but strengthened the relation for truck and bus traffic. The number of toll station workers was relatively small and nonoccupational factors may have had a substantial impact on the urinary 8-OHdG and plasma NO concentrations. Therefore the estimated relations have wide confidence limits.

\section{Synthesis with previous knowledge}

We identified several previous studies that have applied urinary 8-OHdG as biomarkers of oxidative stress in general. The formation of 8-OHdG is related to personal physiological factors (age, gender), environmental exposure (traffic exhaust, sunlight), lifestyle (smoking, betel nut chewing), disease (cancer, systemic lupus erythematosus, arthritis, and diabetes mellitus). ${ }^{15} 162022$ Chuang and colleagues ${ }^{15}$ compared the levels of urinary 8-OHdG between male taxi drivers and male community residents in Taipei, Taiwan. The average level of urinary 8-OHdG was significantly higher in taxi drivers than in community residents (13.4 (4.7) $v 11.5$ (4.7) $\mu \mathrm{g} / \mathrm{g}$ creatinine, mean (SD)). The average 8 -OHdG levels also were higher in smokers than in non-smokers among both the taxi drivers and the community men. In addition, the community men had higher levels of 8-OHdG than that of our reference female group. The 8-OHdG levels for taxi drivers were of similar magnitude compared with our female toll workers. There were no $\mathrm{PM}_{10}$ or $\mathrm{PM}_{2.5}$ levels determined in the study. Based on our previous measurements in the Taipei toll station, ${ }^{23}$ the workers were exposed to very high levels of particles: the median eight hour concentrations of $\mathrm{PM}_{2.5}$ were from 215 to $346 \mu \mathrm{g} / \mathrm{m}^{3}$ in the bus and truck lanes, and from 87 to $130 \mu \mathrm{g} / \mathrm{m}^{3}$ in the car lanes, while the control group was exposed to $50-70 \mu \mathrm{g} / \mathrm{m}^{3}$.

Squadrito and colleagues ${ }^{24}$ hypothesise that semiquinone radical, present in $\mathrm{PM}_{2.5}$, will undergo redox cycling, thereby reducing oxygen and generating ROS. These ROS will cause oxidative stress at the site of deposition and produce deleterious effects in the lung. Ulrich and colleagues ${ }^{14}$ proposed a possible mechanism for PM induced health effects. Briefly, PM will activate alveolar macrophages and epithelial cells to synthesise cytokines. As a consequence, inflammatory cells will be recruited to enhance the inflammatory process. Meanwhile, inducible NO synthase (iNOS) will be induced in the epithelial cells and endothelium. Phagocytosis of the PM by macrophages results in the release of ROS. The induction of iNOS will release a large amount of NO. Thus, both NO and ROS could cause further damage to the surrounding epithelium and endothelium.

The results of the present and one previous ${ }^{15}$ study indicate that plasma NO reflects exposure to traffic related and other types of air pollutants. The average level of plasma NO was higher in the non-smoking drivers $(42.4(6.0) \mu \mathrm{M})$ than in the non-smoking community men (37.7 (7.5) $\mu \mathrm{M}) .{ }^{15}$ In addition, the NO level among the exposed was 13\% higher than that of non-smoking community men, while in our study the difference was $30 \%$ higher. The above evidence suggests the increased plasma NO might be induced by endothelial cell nitric oxide synthase (eNOS). Conversely, others suggest that nitric oxide formed by endothelial NO synthase may be suppressed by traffic exhaust particles. ${ }^{12}$

The plasma NO was not associated with urinary 8-OHdG and 1-OHPG. This may be explained by the different kinetics of these parameters. The levels of $8-\mathrm{OHdG}$ are more likely PAH dependent, whereas NO are probably not. Urinary 1-OHPG has been extensively used as a means for assessing recent exposure to PAHs. The half life is about 6-35 hours. The 8 -OHdG represents the DNA repair process for damage from exposure over a longer time period. The oxidation of PAHs can form electrophilic derivatives that can attack and bind to DNA and may involve ROS. Such changes may include ROS induced DNA strand breaks, base modifications, oxidative modification of DNA, etc. ${ }^{324} 25$ Lai and colleagues ${ }^{8}$ indicated that pyrene concentrations are highest in fine particles. The fine particles in the exhausts of trucks and buses have a higher content of pyrene compared with corresponding size fraction of particles from passenger cars. Trucks and buses constitute a stronger source of pyrene exposure by both producing higher concentrations of fine and coarse particles, and by producing fine particles with higher concentration of pyrene. These might explain why the adjusted increase of 8-OHdG in relation to cumulative or average traffic density was greater for trucks and buses compared to personal cars.

The presence of the 8-OHdG in urine represents the primary repair product of oxidative DNA damage in vivo, presumably nucleotide excision repair. ${ }^{26}{ }^{27} \mathrm{Hu}$ and colleagues $^{28}$ indicate that N45 overestimates 8 -OHdG levels. It is important to note that they also showed that levels determined by ELISA using N45 correlates well with their LC/MS/MS method. Thus, while ELISA is less accurate than the new method, we still see a difference between exposed and non-exposed subjects. It would be of interest to use more advanced methods of analysis for 8-OHdG in these subjects in the future.

There is substantial individual variability in the repair of DNA, which has not been carefully quantified. ${ }^{29}{ }^{30}$ A comparison of variation within and between individuals in controlled exposure conditions would provide important insight to the usefulness of 8-OHdG as a biomarker of oxidative stress caused by exposure traffic exhausts. Furthermore, this approach does not identify or chemically characterise specific adducts. There is empirical evidence, including genetic and nutritional factors, suggested to influence 8-OHdG metabolism, that was not taken into account in this study. Kristenson and colleagues ${ }^{16}$ reported 
that lower serum antioxidants in Lithuanian men, such as $\alpha$ and $\beta$-carotene, were inversely correlated to urinary 8 -OHdG. The human MutT homologue (hMTHl) is a representative of the class of 8-OHdG repair enzymes, which prevents the cell from incorporating 8-OH-Gua into DNA by hydrolysing 8-OH-dGTP to 8 -OH-dGMP. ${ }^{31}$

\section{Conclusions}

Our results indicate that exposure to traffic exhausts increases the urinary concentration of $8-\mathrm{OHdG}$, suggesting that it might be a useful biomarker of oxidative stress from vehicle exhaust exposure. Exposure to traffic exhausts may induce endothelial cell nitric oxide synthase, leading to increase in plasma NO concentrations and pathophysiological changes in vascular tone. Further studies are needed to elaborate the within individual relation between exposure to traffic exhausts and urinary 8-OHdG concentration and to clarify the source of plasma NO.

\section{Authors' affiliations}

C-H Lai, S-H Liou, T Yang, Department of Public Health, National Defence Medical Center, Taipei, Taiwan 114, ROC

H-C Lin, Department of Pharmacology, National Defence Medical Center, Taipei, Taiwan 114, ROC

T-S Shih, Institute of Occupational Safety and Health, Council of Labour Affairs, Executive Yuan, Taipei, Taiwan 221, ROC

P-J Tsai, Department of Environmental and Occupational Health, National Cheng Kung University, Tainan, Taiwan 70428, ROC

J-S Chen, Tri-Service General Hospital, Department of Internal Medicine, Division of Nephrology, Taipei, Taiwan 114, ROC

J J K Jaakkola, Institute of Occupational and Environmental Medicine, The University of Birmingham, Edgbaston, Birmingham B15 2TT, UK

P T Strickland, Department of Environment Health Sciences, Johns Hopkins Bloomberg School of Public Health, Baltimore, MD 21205, USA

Funding: this research was supported by the National Science Council in Taiwan (NSC 92-2320-B-016-062)

Competing interests: none declared

\section{REFERENCES}

1 Donaldson K, Stone V, Seaton A, et al. Ambient particles inhalation and the cardiovascular system: potential mechanisms. Environ Health Perspect 2001; 109(suppl 3):P523

2 Frampton MW. Systemic and cardiovascular effects of airway injury and inflammation: ultrafine particle exposure in humans. Environ Health Perspect 2001; 109(suppl 3):P529

3 Wiseman H, Halliwell B. Damage to DNA by reactive oxygen species and nitrogen species: role in inflammatory disease and progression to cancer. Biochem J 1996:313:17-29.

4 Halliwell B, Cross CE. Oxygen-derived species: their relation to human disease and environmental stress. Environ Health Perspect 1994; 102(suppl 10):P5.

5 Hung HF, Wang CS. Experimental determination of reactive oxygen species in Taipei aerosols. J Aerosol Sci 2001;32:1201-11.

6 Allen JO, Dookeran NM, Smith KA, et al. Measurement of polycyclic aromatic hydrocarbons associated with size-segregated atmospheric aerosols in Massachusetts. Environ Sci Technol 1996;30:1023-31.

7 Strickland P, Kang D. Urinary 1-hydroxypyrene and other PAH metabolites as biomarkers of exposure to environmental PAH in air particulate matter. Toxicol Lett 1999; 108:191-9.

8 Lai CH, Liou SH, Shih TS, et al. Concentration of pyrene in relation to aerosol size distribution in traffic exhausts. Arch Environ Health 2003;58:624-32.
9 International Agency for Research on Cancer. Polynuclear aromatic compounds. Part 1. Bitumens, coal tars and derived products, shale oils and soots. In: IARC monographs on the evaluation of carcinogenic risk of chemicals to humans, Vol. 32. Lyon: IARC, 1985.

10 Lai CH, Liou SH, Shih TS, et al. Urinary 1-hydroxypyrene-glucuronide as a biomarker of exposure to traffic exhausts among highway toll station workers. Arch Environ Health. In press.

11 Casillas AM, Hiura T, Ning L, et al. Enhancement of allergic inflammation by diesel exhaust particles: permissive role of role oxygen species. Enhancement of allergic inflammation by diesel exhaust particles: permissive role of reactive oxygen species, Ann Allergy Asthma Immunol 1999;83:624-9.

12 Kumagai Y, Shimojo N. Possible mechanisms for induction of oxidative stress and suppression of systemic nitric oxide production caused by exposure to environmental chemicals. Environ Health Prev Med 2002;7:141-50.

13 Moncada S, Palmer RMJ, Higgs EA. Nitric oxide: physiology, pathophysiology, and pharmacology. Pharmacol Rev 1991;43:109-42.

14 Ulrich MM, Alink GM, Kumarathasan P, et al. Health effects and time course of particulate matter on the cardiopulmonary system in rats with lung inflammation. J Toxicol Environ Health A 2002;65:1571-95.

15 Chuang CY, Lee CC, Chang YK, et al. Oxidative DNA damage estimated by urinary 8-hydroxydeoxyguanosine: influence of taxi driving, smoking and areca chewing. Chemosphere 2003;52:1163-71.

16 Kristenson M, Kucinskiene Z, Schafer-Elinder L, et al. Lower serum levels of beta-carotene in Lithuanian men are accompanied by higher urinary excretion of the oxidative DNA adduct, 8-hydroxydeoxyguanosine. The LiVicordia study. Nutrition 2003;19:11-15.

17 Kuo HW, Chang SF, Wu KY, et al. Chromium (VI) induced oxidative damage to DNA: increase of urinary 8-hydroxydeoxyguanosine concentrations (8$\mathrm{OHdG}$ ) among electroplating workers. Occup Environ Med 2003;60:590-4.

18 Strickland PT, Kang D, Bowman ED, et al. Identification of 1-hydroxypyrene as the major pyrene metabolite in human urine by synchronous fluorescence spectroscopy and gas chromatography-mass spectrometry. Carcinogenesis 1994; 15:483-7.

19 Kang DH, Rothman N, Poirier MC, et al. Interindividual differences in the concentration of 1-hydroxypyrene-glucuronide in urine and polycyclic aromatic hydrocarbon-DNA adducts in peripheral white blood cells after charbroiled beef consumption. Carcinogenesis 1995;16:1079-85.

20 Maeshima $\mathrm{E}$, Liang XM, Otani $\mathrm{H}$, et al. Effect of environmental changes on oxidative deoxyribonucleic acid (DNA) damage in systemic lupus erythematosus. Arch Environ Health 2002;57:425-8.

21 Lin HC, Kang BH, Wong CS, et al. Systemic administration of D-amphetamine induced a delayed production of nitric oxide in the striatum of rats. Neuro Lett 1999;276:141-4.

22 Loft S, Vistisen K, Ewertz M, et al. Oxidative DNA damage estimated by 8-hydroxydeoxyguanosine excretion in humans: influence of smoking, gender and body mass index. Carcinogenesis 1992;13:2241-7.

23 Lai CH, Liou SH, Shih TS, et al. Exposure to fine particulate matter (PM2.5) among highway toll workers in Taipei. Arch Environ Health. In press.

24 Squadrito GL, Cueto R, Dellinger B, et al. Quinoid redox cycling as a mechanism for sustained free radical generation by inhaled airborne particulate matter. Free Radic Biol Med 2001;31:1132-8.

25 Tokiwa H, Sera N, Nakanishi Y, et al. 8-Hydroxyguanosine formed in human lung tissues and the association with diesel exhaust particles. Free Radic Biol Med 1999;27:1251-8.

26 Cooke MS, Evans MD, Herbert KE, et al. Urinary 8-oxo-2'-deoxyguanosine by exposure to reactive oxygen-generating substances. Free Radic Biol Med 2000:32:381-97.

27 Rozalski R, Gackowski D, Roszkowski K, et al. The level of 8-hydroxyguanine, a possible repair product of oxidative DNA damage, is higher in urine of cancer patients than in control subjects. Cancer Epidemiol Biomark Prev 2002:11:1072-5.

28 Hu CW, Wu MT, Chao MR, et al. Comparison of analyses of urinary 8-hydroxy-2'-deoxyguanosine by isotope-dilution liquid chromatography with electrospray tandem mass spectrometry and by enzyme-linked immunosorbent assay. Rapid Commun Mass Spectrom 2004;18:505-10.

29 Matullo G, Palli D, Peluso M, et al. XRCC3, XPD gene polymorphisms, smoking and (32)P-DNA adducts in a sample of healthy subjects. Carcinogenesis 2001;22:1437-45.

30 Palli D, Russo A, Masala G, et al. DNA adduct levels and DNA repair polymorphisms in traffic-exposed workers and a general population sample. Int J Cancer 2001;94:121-7.

31 Sato $Y$, Nanri H, Ohta $M$, et al. Increase of human MTH1 and decrease of 8-hydroxydeoxyguanosine in leukocyte DNA by acute and chronic exercise in healthy male subjects. Biochem Biophys Res Commun 2003;305:333-8. 